\title{
Carbon Stock Variations Along Altitudinal and Slope Gradient in the Forest Belt of Simen Mountains National Park, Ethiopia
}

\author{
Tibebu Yelemfrhat Simegn ${ }^{1, *}$, Teshome Soromessa ${ }^{2}$ \\ ${ }^{1}$ Ethiopian Wildlife conservation Authority, Addis Ababa, Ethiopia \\ ${ }^{2}$ Center of Environmental Science, Addis Ababa University, Addis Ababa, Ethiopia
}

Email address:

tibes27@yahoo.com (Simegn T. Y.)

\section{To cite this article:}

Tibebu Yelemfrhat Simegn, Teshome Soromessa. Carbon Stock Variations Along Altitudinal and Slope Gradient in the Forest Belt of Simen Mountains National Park, Ethiopia. American Journal of Environmental Protection. Vol. 4, No. 4, 2015, pp. $199-201$.

doi: $10.11648 /$ j.ajep.20150404.15

\begin{abstract}
Forests play a significant role in climate change mitigation by sequestering and storing more carbon from the atmosphere which is released by anthropogenic causes. The overall objective of this study was to measure Variations of Carbon Stock along Altitudinal and Slope Gradient in the forest belt of Simen Mountains National Park. And it aimed to add values of the lowland forest belt of the park for climate change mitigation contribution in Ethiopia. The work was accomplished properly using random sampling to estimate the forest carbon in above and below ground biomass by considered each trees and shrubs which had DBH $\geq 5 \mathrm{~cm}$. Above ground biomass was estimated by using allometric models equation while below ground biomass was determined based on the ratio of below ground biomass to above ground biomass factors. Dead wood, leaf litter, herb and grass (LHG) and soil organic carbon were conducted according to sampling quadrates data and laboratory result. The results shown that, there were twenty species with a density of 2334 trees and shrubs in the study sites which had DBH $\geq 5 \mathrm{~cm}$. The mean above ground and below ground biomass carbon stock were $270.89 \pm 154.50$ and $54.18 \pm 30.81 \mathrm{t} \mathrm{ha}^{-1}$ respectively. The $^{-2}$ mean above ground biomass carbon per species was $20.42 \pm 17.99 \mathrm{t} \mathrm{ha}^{-1}$. The mean carbon in dead wood, LHG and soil carbon were $0.7258 \pm 1.0479,0.019 \pm 0.008$ and $242.51 \pm 46.42 \mathrm{t} \mathrm{ha}^{-1}$ respectively. The total Carbone stock variation along altitudinal gradient was 542.6, 550.73 and $627.01 \mathrm{t} \mathrm{ha}^{-1}$ for upper, mid and lower altitude respectively by which higher amount of carbon was stored in lower altitude. The total carbon stock variation along slope gradient was $487.3,557.00$ and $625.877 \mathrm{tha}^{-1}$ for upper, mid and lower slope respectively by which higher amount of carbon was stored in lower altitude. So that in this study both altitude and slope had the same impact on carbon stock potential of the species in the areas of study.
\end{abstract}

Keywords: Allometric models, Anthropogenic causes, Biomass carbon, Mitigation, Simen Mountains National Park

\section{Introduction}

Carbon sequestration is the process of removing excess carbon dioxide $\left(\mathrm{CO}_{2}\right)$ from the atmosphere and depositing it in a reservoir [1]. It is a way to mitigate the accumulation of greenhouse gases in the atmosphere released by the burning of fossil fuel and other anthropogenic activities. Through biological, chemical or physical processes, $\mathrm{CO}_{2}$, which is one of the greenhouse gases, can be captured from the atmosphere. While a carbon sink is a reservoir that collects and stores carbon containing chemical compound, it removes $\mathrm{CO}_{2}$ from the atmosphere through absorption. Forest and soil are potential sinks for elevated $\mathrm{CO}_{2}$ emissions and are being considered in the list of acceptable offsets [1]. Sustainable forest development and forested landscape expansion is one of the key approaches for reducing atmospheric carbon concentration. It is a safe, environmentally acceptable, and cost-effective way to capture and store substantial amounts of atmospheric carbon. The concurrent development of tradable carbon credits provides financial incentives for considering carbon storage in forest management decisions [2].

Carbon sequestration from atmosphere can be advantageous from both environmental and socio-economic perspectives. There are evidences from several studies in Ethiopia and other countries. The environmental perspective includes the removal of $\mathrm{CO}_{2}$ from the atmosphere [3], the 
improvement of soil quality [4], and the increase in biodiversity[5]; while socioeconomic benefits include increased yields [6], monetary incomes from potential carbon trading schemes [7], normalizing droughts through its potential for creating atmospheric condensation making cloud seeding, as well as reducing flood hazards and increasing ground water recharge by increasing water infiltration through soil columns. Globally, forests act as a natural storage for carbon, contributing approximately $80 \%$ of terrestrial above-ground, and $40 \%$ of terrestrial belowground biomass carbon storage [8]. So biomass is an important element in the carbon cycle, specifically carbon sequestration. It is used to help to quantify pools and fluxes of greenhouse gases (GHG) from the terrestrial biosphere to the atmosphere associated with land use land cover changes [9]. There are many conventional methods for quantification of sequestered carbon. Many of these methods are complicated, expensive and limited in their coverage. Such limitations impede sound quantification and monitoring of carbon [10]. One of such approaches is forest inventory data sets which often provide the required base line data to enable the large area mapping of biomass and subsequent carbon accounting over a range of spatial and temporal scales. However, spatially explicit estimates of biomass over large areas may be limited by the spatial extent of the forest inventory relative to the area of interest (i.e., inventories not spatially exhaustive), or by the omission of inventory attributes required for biomass estimation. These spatial and attribution gaps in the forest inventory may result in an underestimation of large area biomass [11].

This research was conducted with the aim of understanding carbon stock variations along altitudinal and slope gradient in different carbon pools of the forest ecosystem Simen Mountains National Park, Ethiopia

\section{Materials and Methods}

\subsection{Description of the Study Area}

This study was undertaken in lowland forest of Simen mountains national park forest, Amhara National Regional State, North Gondar, Ethiopia located at about $846 \mathrm{~km}$ North of Addis Ababa. The forest has an altitudinal gradient ranging from 1900 to $3000 \mathrm{~m}$ above sea level with the highest peak at Ras dashin Mountain. The forest covers 171 hectares. The study area is characterized by moderate climate, locally known as woina dega and it has a mono modal rainfall distribution and the rainy season is from June to August with The annual average rain fall of SMNP $1367 \mathrm{~mm}$ and the mean annual maximum and minimum temperatures are $11^{\circ} \mathrm{C}$ and $19^{\circ} \mathrm{C}$, respectively.

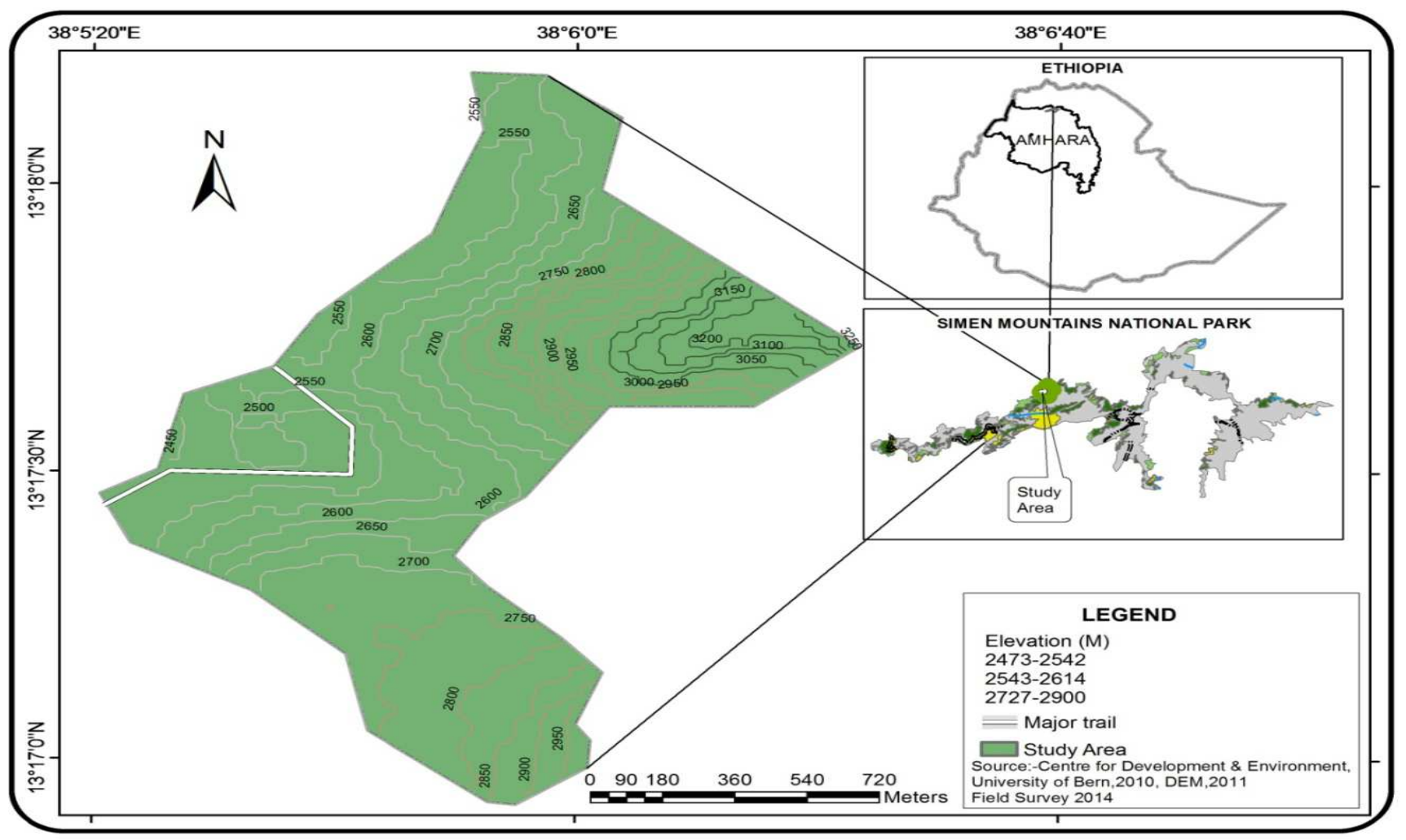

Figure 1. Map of the study area

\subsection{Delineation of the Study Site}

Delineation of the forest boundaries was the first step in forest carbon stock measurement. The boundary of the study forest area was delineated by taking geographic coordinates with GPS at each turning point. The GPS points that were taken from the study site to indicate each sample plots were recorded. 


\subsection{Sampling Techniques on the Field}

Simple random sampling method was used to take samples. Sample plots were laid along line transects based on altitudinal variation of the study area. A randomly sampling plot of $(10 \mathrm{~m} \times 20 \mathrm{~m})$ in each site was established. To reveal the tree composition and biomass, all live trees with a diameter $\geq 5 \mathrm{~cm}$ were recorded as indicated by [12]. The diameter was measured at breast height (DBH, $1.3 \mathrm{~m}$ height from the ground) to estimate biomass and the size class distribution of trees in a sampling plot. DBH was measured by using tree measuring tape. Trees with multiple stems connected near the ground were counted as single individuals and bole circumference was measured separately. Tree height was recorded by using measuring clinometers. The methodology and procedures used to estimate carbon stocks were simple step by step procedures using standard carbon inventory principles and techniques [12]. Procedures were based on data collection and analysis of carbon accumulating in the above ground biomass, below-ground biomass, leaf litter, and soil carbon of forests using verifiable modern methods.

\subsection{Stratification of the Study Area}

Stratification was done in the forest in order to take accurate data from the field as well as to maintain the homogeneity of the area. Altitude was the major parameter to classify the study area. The strata were defined at each elevation, starting from the bottom to the top of the mountain. Based on altitudinal variation, the study site was stratified into three zones namely: lower (2473-2542 m), middle (2543-2614 m) and higher $(2615-2900 \mathrm{~m})$. Slope gradient was the second parameter to classify the area. Therefore, slope classes classified into lower (0-10\%), middle (>10-20\%) and higher $(>20 \%)$. Aspect was also another parameter that was considered in the study forest and classified in to four classes: N (North), S (South), E (East), W (West).

\subsection{Field Measurements}

Sample plots $(10 \mathrm{~m} \times 20 \mathrm{~m})$ were laid through stratified random sampling method with nine transect lines in the various qualitatively classified biomass levels to account for the largest variability in the biomass range. Ground inventory data of tree parameters i.e., DBH and height of the trees were collected.

\subsubsection{Vegetation Data Collection and Identification}

The estimations of above and below ground carbon depend on the above ground biomass of living tree species. To estimate the above ground biomass all tree species within selected sample plots $\mathrm{DBH} \geq 5 \mathrm{~cm}$ were identified and recorded. Trees with multiple stems at $1.3 \mathrm{~m}$ height were treated as a single individual and DBH of the largest stem was taken. Plant identification was done by using Flora of Ethiopia and Eritrea.

\subsubsection{Field Carbon Stock Measurement}

The major activities of carbon measurement during the field data collection were above-ground tree biomass, belowground biomass, leaf litter, and soil organic carbon measurements. Detailed methods are explained under the following sub headings.

\section{(i). Above Ground Biomass (AGB)}

The above ground biomass consists of all living vegetation above the soil, inclusive of stems, stumps, branches, bark, seeds and foliage. The DBH (at $1.3 \mathrm{~m}$ ) and height of individual trees greater than or equal to $5 \mathrm{~cm}$ and $\mathrm{DBH}$ were measured in each sampling plots.

\section{(ii). Litter Biomass (LB)}

The leaf litter is defined as all dead organic surface material on top of the mineral soil. A quadrate with a size of $1 \mathrm{~m} \times 1 \mathrm{~m}$ was established to sample litters. In each sample plots a total of five small quadrates were laid four at the corner and one in the center to minimize heterogeneity. The litter samples were taken in sub quadrate of $(1 \mathrm{~m} \times 1 \mathrm{~m})$ along diagonal from one corner to the other and then the leaf litters within the $1 \mathrm{~m}^{2}$ sub plots were collected. Laboratory analysis: The 100 gram sub sample fresh weights were sampled from the five sub-samples collected from each quadrant which were mixed homogenously and then taken to laboratory and oven dried at $105^{\circ} \mathrm{c}$.

\section{(iii). Soil Organic Carbon (SOC)}

Soil samples were collected from the field with five subplots within each major plot. The Samples were dug using core sampler with a diameter of $5 \mathrm{~cm}$ and the depth of the soil in which that took the sample was $30 \mathrm{~cm}$. Mixing of soils was done properly by taking equal amount of soil from each sub plots to make a composite in order to make homogeneity. After organizing the samples in such a way, the samples were taken to Wondo Genet College of forestry and Natural resources for laboratory analysis. In the laboratory, soils are prepared and oven dried at $105^{\circ} \mathrm{c}$ for 24 hours to remove the soil moisture so as to determine the percentage of organic carbon. Finally, the bulk density and soil organic carbon were determined after getting percentage of organic carbon.

\subsubsection{Estimation of Carbon Stocks in Different Carbon Pools}

\section{(i). Estimation of Above Ground Carbon Stock (AGC)}

As defined by [13]; allometric equation as a statistical relationship between key characteristic dimensions of trees that are fairly easy to measure, such as $\mathrm{DBH}$ or height, and other properties that are more difficult to assess, such as above ground biomass. The equation developed by [14], was used to calculate the above ground biomass as given below:

$$
\mathrm{AGB}=34.4703-8.0671(\mathrm{DBH})+0.6589(\mathrm{DBH} 2)
$$

Where, AGB is above ground biomass, $\mathrm{DBH}$ is diameter at breast height. 


\section{(ii). Estimation of Below Ground Carbon Stock (BGC)}

Below ground biomass estimation is much more difficult and time consuming than estimating aboveground biomass [15]. Roots play an important role in the carbon cycle as they transfer considerable amounts of Carbon to the ground, where it may be stored for a relatively long period of time. As indicated by [10], standard method for estimation of below ground biomass can be obtained as $20 \%$ of above ground tree biomass i.e., root to shoot ratio value of 1:5 is used. The equation is given below:

$$
\mathrm{BGB}=\mathrm{AGB} \times 0.2
$$

Where, $\mathrm{BGB}$ is below ground biomass, $\mathrm{AGB}$ is above ground biomass, 0.2 is conversion factor (or $20 \%$ of $A G B$ ).

\section{(iii). Estimation of Carbon Stocks in Dead Wood}

The allometric equation confirmed in REDD methodology (2009) was used to estimate the amount of biomass in standing dead wood.

$$
\operatorname{BSDW}=\sum_{\mathrm{i}=0}^{\mathrm{n}} 1 / 3(\mathrm{D} / 200)^{2} \mathrm{~h}^{*} \mathrm{~s}
$$

Where, biomass is expressed in $\mathrm{kg}$,

$\mathrm{h}=$ length $(\mathrm{m}), \mathrm{D}=$ tree diameter $(\mathrm{cm})$ and

$\mathrm{s}=$ specific gravity $(\mathrm{g} \mathrm{cm}-3)$ of wood. The specific density is estimated at $0.5 \mathrm{~g} \mathrm{~cm}^{-3}$ as default value, but can be around 0.8 for dense hard woods and around 0.3 for very light species in tropical regions [16].

The carbon content in dead wood is calculated by multiplying total biomass of dead wood with the [17] default carbon fraction of 0.47 .

\section{(iv). Estimation of Carbon Stocks in the Litter Biomass}

According to Pearson et al. (2005), estimation of the amount of biomass in the leaf litter can be calculated by:

$$
\text { LHGB }=\frac{\text { Wfield }}{\mathrm{A}} * \frac{\text { Wsub }_{\text {sample(dry) }}}{\text { Wsub }_{\text {sample(fresh })}} * \frac{1}{10,000}
$$

Where: $\mathrm{LB}=$ Litter biomass $\left(\mathrm{ha}^{-1}\right)$

$\mathrm{W}$ field $=$ Weight of wet field sample of litter sampled within an area of size $1 \mathrm{~m}^{2}(\mathrm{~g}) ; \mathrm{A}=$ Size of the area in which litter were collected (ha);

W sub-sample, dry = Weight of the oven-dry sub-sample of litter taken to the laboratory to determine moisture content (g), and

W sub-sample, fresh $=$ Weight of the fresh sub-sample of litter taken to the laboratory to determine moisture content (g). The carbon content of vegetation is surprisingly constant across a wide variety of tissue types and species. [18] noted that Carbon content of biomass is almost always found to be between 45 and $50 \%$ (by oven dry mass). In many applications, the carbon content of vegetation is estimated by simply taking a fraction of the biomass by multiplying 0.5 .

$\mathrm{C}=0.5^{*}$ LB Where $\mathrm{C}=$ is carbon content by mass, and $\mathrm{LB}=$ is oven-dry biomass.

Therefore, total carbon content of litter (ton/ha) =Total dry litter biomass* carbon fraction

$$
\mathrm{CL}=\mathrm{LBM} \times \% \mathrm{C}
$$

Where, CL is total carbon stocks in the litter in ton/ha,

$\% \mathrm{C}$ is carbon fraction determined in the laboratory (Pearson et al., 2005).

\section{(v). Estimation of Soil Organic Carbon (SOC)}

The carbon stock of soil was done by using the following formula which is recommended by [12] from the volume and bulk density of the soil.

$$
\mathrm{V}=\mathrm{h} \times \prod \mathrm{r}^{2}
$$

Where, $\mathrm{V}$ is volume of the soil in the core sampler in $\mathrm{cm}^{3}$, $\mathrm{h}$ is the height of core sampler in $\mathrm{cm}$, and $\mathrm{r}$ is the radius of core sampler in $\mathrm{cm}$ [12]. More over the bulk density of a soil sample was calculated as follows:

$$
\mathrm{BD}=\mathrm{Wav}, \mathrm{dry} / \mathrm{V}
$$

Where, BD is bulk density of the soil sample per, Wav, dry is average air dry weight of soil sample per the quadrant, $\mathrm{V}$ is volume of the soil sample in the core sampler auger in $\mathrm{cm}^{3}$ [12].

$$
\mathrm{SOC}=\mathrm{BD} * \mathrm{D} * \% \mathrm{C}
$$

Where, $\mathrm{SOC}=$ soil organic carbon stock per unit area ( $\mathrm{t}$ ha1) $\mathrm{BD}=$ soil bulk density $\left(\mathrm{g} \mathrm{cm}^{-3}\right)$,

$\mathrm{D}=$ the total depth at which the sample was taken $(30 \mathrm{~cm})$, and $\% \mathrm{C}=$ Carbon concentration $(\%)$.

\subsubsection{Estimation of Total Carbon Stock Density}

The total carbon stock is calculated by summing the carbon stock densities of the individual carbon pools of the stratum using the [12] formula. Carbon stock density of a study area:

$$
\mathrm{CT}=\mathrm{AGC}+\mathrm{BGC}+\mathrm{LC}+\mathrm{SOC}
$$

Where, CT $=$ Total Carbon stock for all pools (ton/ha), $\mathrm{AGC}=$ above ground carbon stock (ton/ha), $\mathrm{BGC}=$ below ground carbon stock (ton/ha), LC=litter carbon stock (ton/ha) and $\mathrm{SOC}=$ soil organic carbon (ton $/ \mathrm{ha})$. The total carbon stock was then converted to tons of $\mathrm{CO}^{2}$ equivalent by multiplying it by $44 / 12$, or 3.67 as indicated by [19].

\section{Data Analysis}

After the data collection was completed, data analysis of various carbon pools measured in the forests were accomplished by organizing and recording on the excel data sheet. The data obtained from $\mathrm{DBH}$, diameter, height of each species, field weight $\left(\mathrm{W}_{\mathrm{w}}\right)$, fresh weight-(FW) and dry weight $\left(\mathrm{W}_{\mathrm{dry}}\right)$ of LHG and soil were organized by excel 2007 and analyzed using and MINITAB software version 16 . DBH data was arranged in classes $\leq 10,>10-20,>20-30,>30-40$ and $>40$ for applying appropriate model of biomass estimation equation. The relationship between each parameter was tested by descriptive statistics. Differences at the $95 \%(\alpha=0.05)$ confidence interval was used to see the 
significance differences.

\section{Results}

\subsection{Carbon Stocks of Different Pools Along Altitudinal Variation}

The presence of variation in altitudinal gradient affects the carbon stock of different pools in the forest. The lower parts of altitude is high in above ground carbon stocks while the upper and middle parts of altitude have low to moderate carbon stocks in above ground biomass. 318.8174, 258.247 and 240.6356 ton/ha carbon stocks were recorded at the lower, middle and upper altitude respectively.

Similar trend was shown in below ground biomass in which $63.76,51.65$ and 51.64 ton/ha carbon stocks were recorded in the lower, middle and upper altitude respectively with highest value found at the lower part of altitudinal classes followed by the middle and upper parts. But this is not very much significance at $95 \%$ confidence interval $(\mathrm{F}=$ 0.618, $\mathrm{P}=0.543)$ in $\mathrm{AGC}$ and $(\mathrm{F}=0.618, \mathrm{P}=0.543)$ in $\mathrm{BGC}$ stocks. It is also the same in the case of litter carbon stock and SOC. With significance difference at $\alpha=0.059$ ( $\mathrm{F}=0.991$, $\mathrm{P}=0.378)$ in litter carbon stock and $(\mathrm{F}=0.653, \mathrm{P}=0.525) \mathrm{SOC}$ stocks. The litter and SOC carbon stock were higher in the lower parts of altitude and low in the upper altitude. 243.943, 240.3293 and 240.1949 ton/ha stocks of carbon were recorded in the lower, middle and upper altitude respectively in the soil pool. In general, the lower part of the altitude contains more carbon stocks (243.943 ton/ha), followed by the middle (240.329 ton/ha) and the upper altitudinal gradient (240.194 ton/ha).

\subsection{Carbon Stocks of Different Pools Along Slope Gradient}

The slope gradient was also a second factor which affects the carbon stocks of different pools in the studied forest. Above ground biomass and below ground biomass and their consecutive carbon stocks were found to be low in hilly areas of the forest due to the fact that no more vegetation cover were found there. The carbon stock of the middle slope gradient was moderate in both above ground carbon and below ground carbon stocks and higher in the upper slope gradient in both pools. $316.172,260.355$ and 187.128 ton/ha carbon stocks were recorded at the lower, middle and upper slope gradient respectively in above ground carbon stocks. Similar trend was also shown in below ground biomass in which $63.234,52.071$ and 37.426 ton/ha carbon stocks were recorded in the lower, middle and higher slope classes respectively with highest value found at the lower of slope classes followed by the middle and upper slope classes. But this was not statistically significance at $\alpha=0.05(\mathrm{~F}=0.169, \mathrm{P}=$ $0.845)$ in above ground biomass and $(\mathrm{F}=0.169, \mathrm{P}=0.845)$ in below ground biomass. At the same in the case of dead wood, litter carbon stock and SOC, there was no significance difference at $\alpha=0.05$. The litter carbon stock was higher in the lower slope classes and low in the higher slope classes with its value arranged $0.020,0.0171$ and $0.017 \mathrm{ton} / \mathrm{ha}$ in the lower, middle and higher slope gradient respectively. The carbon stock in the soil pool was higher in lower slope classes and lower in the upper slope classes with moderate carbon stocks in the middle slope classes. 246.417, 244.453 and 240.974 ton/ha stocks of carbon were recorded in the lower, middle and upper slope classes respectively in the soil pool. However for dead wood carbon stock higher carbon stock in higher slope class (1.466 ton/ha) with lower in the lower slope class $(0.290)$ and moderate stock in the middle slope class $(0.421$ ton/ha).

Table 1. Mean biomass and carbon stocks ( $t$ ha-1) in different carbon pools along altitudinal range

\begin{tabular}{|c|c|c|c|c|c|c|c|c|}
\hline Altitude class & Altitude range (m) & No of Plots & AGC & BGC & $\mathbf{L C}$ & DWC & SOC & Total carbon (ton/ha) \\
\hline Upper & $2615-2900$ & 17 & 240.635 & 51.6494 & 0.459 & 0.016 & 240.195 & 542.582 \\
\hline Middle & $2543-2614$ & 19 & 258.247 & 48.1271 & 0.255 & 0.017 & 240.329 & 550.73 \\
\hline Lower & $2473-2542$ & 18 & 318.817 & 63.7635 & 0.896 & 0.021 & 243.943 & 627.014 \\
\hline
\end{tabular}

Table 2. Carbon stocks in different pools with respect to slope gradient

\begin{tabular}{|c|c|c|c|c|c|c|c|c|}
\hline Slope Class & Slope Range (\%) & No of Plots & AGC & BGC & $\mathbf{L C}$ & DWC & SOC & Total carbon (ton/ha) \\
\hline Upper & $>20$ & 22 & 187.128 & 37.426 & 0.017 & 1.466 & 240.974 & 487.396 \\
\hline Middle & $>10-20$ & 23 & 260.355 & 52.071 & 0.017 & 0.421 & 244.453 & 557.005 \\
\hline Lower & $0-10$ & 9 & 316.172 & 63.234 & 0.02 & 0.29 & 246.417 & 625.877 \\
\hline
\end{tabular}

Table 3. One-way ANOVA results with altitude gradients

\begin{tabular}{llll}
\hline gradient & Carbon pools & F-value & P-value \\
\hline & AGC & 0.618 & 0.543 \\
& BGC & 0.618 & 0.543 \\
Altitude & DWC & 3.339 & 0.043 \\
& LC & 0.991 & 0.378 \\
& SOC & 0.653 & 0.525 \\
\hline
\end{tabular}

**B Bold values are significant at $\alpha=0.05(95 \%)$ 
Table 4. One-way ANOVA results with altitude gradients

\begin{tabular}{llll}
\hline gradient & Carbon pools & F-value & P-value \\
\hline & AGC & 0.169 & 0.845 \\
BGC & 0.169 & 0.845 \\
Slope & DWC & 1.107 & 0.338 \\
& LHGC & 0.54 & 0.586 \\
\hline
\end{tabular}

\section{Discussion}

\subsection{Storage of Biomass in Different Pools}

The maximum above ground biomass per plot was 1795.64 ton/ha and the minimum was 162.10 ton/ha. The average biomass stock recorded in above ground biomass was $576.36 \mathrm{ton} / \mathrm{ha}$. The results are more or less similar to the previous researches of above ground biomass of afromontane forest which were 567.2 ton/ ha [20] and 591.00 ton/ ha [21] while it was highly larger than Humbo forest of Wolaita Zone [22]. The average above ground biomass observed from these three location was 574.89 ton/ha. The global above ground biomass in tropical dry and wet forests ranged between 30 275 ton/ha and 213-1173 ton/ha respectively as indicated by [23], which is lower than the above ground biomass of Tara Gedam forest.

In this study, the differences in biomass and carbon accumulation among plots could be largely due to differences in the growth rates of plants as indicated by [24]. Litter constitutes an important flux of soil organic Carbon. The forest litter consisted of a relatively high number of trees, although the density varies among samples and species; in densely populated trees few litters were found due to the closeness of plants each other makes their litter not fall down [25]. The Carbon stocks in the litter of the study forest ranged from 2.6-3.8 ton/ha which were comparable to those reported for tropical seasonal rainforests (1.4 ton/ha) carbon [26] and tropical secondary forest at the Makiling Forest Reserve in the Philippines (1.9 ton/ha) [27]. On the other hand, the litter carbon varies on other tropical forests (2.6-3.8 ton/ha) as reported by [28]. The relatively low quantities of Carbon stored in litter carbon stock in the studied forest may be due to the high decomposition rate as reported in a 10year study by [29] and Seasonal Wild fire distraction in some part of the forest and caring number of cattle during the winter that affect the litter carbon stock directly in the area.

The average values of soil organic carbon in the study area was 242.507 ton/ha, which was similar to the Carbon density estimates of Afromontane Rain Forests of the Eastern Arc Mountains which were found to be between 252 and 581 ton/ha as indicated by [30, 31]. The distribution of Carbon stocks in each sample plot of the study forest is known to vary due to the presence of different tree species, soil nutrient availability, climate, and topography and disturbance regime [32]. This indicates that, the higher soil organic carbon in the soil could sequester more $\mathrm{CO}_{2}$. The bulk density of the soil in this study was found to be $0.78 \mathrm{~g} / \mathrm{cm}^{3}$ minimum value and $0.999 \mathrm{~g} / \mathrm{cm}^{3}$ maximum value with an average value of 0.93 $\mathrm{g} / \mathrm{cm}^{3}$. The presence of low bulk density in the soil indicates that the soil has high potentials to accumulate large amount of organic matter in it [32].

\subsection{Carbon Stocks of Different Pools Along Altitudinal and Slope Gradient}

Most of the time altitudinal and slope gradient were the factors that affect the storages of carbon in different pools. As observed, [33] a strong effect of slope on the SOC stock of a subalpine forest in the Olympic Mountains of Washington state. The carbon stock of the study forest was highest at the lower altitudinal range followed by the medium and lowest at higher altitude of the mountain. This is due to the decreasing of layer of large DBH trees at higher altitudinal range of the forest site and the layer of large DBH trees increases towards the lower altitudinal ranges naturally and trees and shrub deforestation was also higher in upper altitude. Especially, altitudinal variation has an impact on AGC, BGC and SOC stock because of its influence on soil water regime [34]. Similarly the carbon stock of the study forest was increased as the degree of slope gradient decreased. This is due to the inclined arrangement of the study forest that affects both forest biomass and soil nature of the area. Most steep areas were covered by lower plants (grasses, herbs and bushes) which have lower biomass and carbon relatively.

\section{Conclusion}

The study conducted in low land forest of Simen Mountain National Park showed that the forest contains moderately diversified plant species. A total of twenty different species of plants were collected, of which Erica arborea was the dominant in density and Buddeleia polystachya was the least dominant in the study site. Based on DBH and height class distribution the forest has a bit different trends observed in both classes. The densities of tree species decreases as the height class increases but For $\mathrm{DBH}$, it has an irregular pattern. This implies that, the predominance of small sized tree and shrub species in the lower classes than in the upper classes. The analysis of these two parameters in the study forest indicated that higher percentage of number of tree species in the lower than in the higher height frequency 
classes. The carbon stocks of the study site shows a variation among the plots due to the presence of higher biomass in some plots and small biomass in other plots. The average carbon stock of the different carbon pools of this study was almost similar with most researches done in tropics and Ethiopia. The ANOVA result showed that at $95 \%$ confidence interval, the carbon stocks in the different carbon pools (AGC, BGC, DWC, LHGC and SOC) were different due to environmental factors (altitude and slope). The lower parts of altitude class carbon stock potential were higher in all pools (except for the DWC pool which is significant for most carbon pools) while the upper and medium parts of altitude had low to moderate carbon stock. This is due to the fact that there were dense vegetation cover in the lower altitudinal range and the presence of favorable conditions in this part. DWC was higher in higher altitude and low to moderate in medium and lower altitude. This is because the higher altitude part of the forest was under less nutrient and different environmental factors like landslide and erosions that facilitate dead wood accumulation. At same time the litter and soil carbon stocks were higher in the lower parts of altitude and slope with lower in the higher altitude due to the presence of large decides forest and by the nature of the lower part to receive the medium and higher feeds to down. The carbon stock of the higher slope gradient was lower in all four pools (AGC, BGC, LHGC, and SOC) and higher to moderate stock in lower and medium slope gradients. This is because the better density of the study forest was found in lower and medium slope area due to the presence of stable environmental conditions better relative disturbance. But DWC was higher in higher slope because environmental pressure is high in this range which affects plant life span.

\section{References}

[1] UNFCCC,'Kyoto Protocol to the United Nation Framework Convention on Climate Change". Retrieved 18/09/2010, from http://unfccc.int. University Press, Cambridge,UK 1997.

[2] Siry, J., Bettinger, P., Borders, B., Cieszewski, C., Clutter, M., Izlar, B., Markewitz, D. and Teskey, R, "Forest Carbon Estimation Protocol for the State of Georgia”, USA 2006.

[3] Yetebitu Moges, Zewdu Eshetu and Sisay Nune, "Manual for assessment and monitoring of carbon in forest and other land uses in Ethiopia" Ethiopian Forest Research Center, Addis Ababa, Ethiopia 2010.

[4] Zewedu Eshetu "Forest soils of Ethiopian highlands: Their characteristics in relation to site history". Doctorial thesis, Swedish University of Agricultural Sciences, Sweden 2000.

[5] Batjes, N.H. and Sombroek, W.G." Possibilities for carbon sequestration in tropical and subtropical soils." Global Change Biology 1997 3: pp,161-173.

[6] Sombroek, W.G., Nachtergaele, F.O. and Hebel, A,”Amounts, dynamics and sequestering of carbon in tropical and subtropical soils". 1993, 22: 417-426.

[7] McDowell, N, "Developing countries to gain from carbon trading fund", Climate Change Mitigation: Cam bridge, U.K.:
Cambridge University Press 2002.

[8] Kirschbaum, M.U.F. "The carbon sequestration potential of tree plantations in Australia" In: (eds.), Environmental Management: The Role of Eucalypts and Other Fast Growing Species, Eldridge, K.G., Crowe, M.P., Old, K.M. Forestry and Forest Products, $1996,20: 77-89$.

[9] Cairns, M. A., Brown, S., Helmer, E. H., Baumgardner, G. A, "Root biomass allocation in the world"s upland forests", Oecologia 111: 1-11, 2003.

[10] MacDicken, K. G, "A Guide to Monitoring Carbon Storage in Forestry and Agro- forestry Projects. In", Forest Carbon Monitoring Program. Winrock International Insti-tute for Agricultural Development, Arlington, Virginia 1997.

[11] Wulder, M.A., White, J.C., Fournier, R.A., Luther, J.E., and Magnussen, S, "Spatially Explicit Large Area Biomass Estimation", Three Approaches Using Forest Inventory and Remotely Sensed Imagery in a GIS 2008, 8:529-560.

[12] Pearson, T., Walker, S. and Brown, S, "Sourcebook for landuse, land-use change and forestry projects": Win rock International and the Bio-carbon fund of the World Bank. Arlington, USA, pp. 19-35, 2005.

[13] Bhishma, P.S., Shiva, S.P., Ajay, P., Eak, B.R., Sanjeeb, B., Tibendra, R.B., Shambhu, C. and Rijan, T, "Forest Carbon Stock Measurement: Guidelines for Measuring Carbon Stocks in Community Managed Forests": $2^{\text {nd }}$ ed. International Centre for Integrated Mountain Development, Asia Network for Sustainable Agriculture and Bioresearches, Federation of Community Forest Users, Kathmandu, Nepal, pp. 15-36, 2011.

[14] Brown, S.A.J., Gillespie, J.R. \& Lugo, A.E, "Biomass estimation methods for tropical forests with application to forest inventory data". For. Sci., 35(4): 881-902, 1989.

[15] Russell AE, Raich JW, Valverde OJ, Fisher RF “Tree species effects on soil properties in experimental plantations in tropical moist forest" Soil Sci Soc Am J 71:1389-1397, 2007.

[16] Hairiah, K., Sitompul, S.M. van Noordwijk M. and Palm C, "Methods for sampling carbon stocks above and below ground" International Centre for Research in Agroforestry; Bogor, Indonesia 2001.

[17] Intergovernmental Panel on Climate Change (IPCC). "Guidelines for National Greenhouse Gas Inventories" National Greenhouse Gas Inventories Program, IGES, Japan 2006.

[18] Schlesinger, W.H, "Biogeochemistry, an Analysis of Global Change", New York, USA, Academic Press 1991.

[19] Pearson, T. R., Brown, S. L. and Birdsey, R. A, "Measurement guidelines for the sequestration of forest carbon", Northern research Station, Department of Agriculture, 2007, Washington, D.C, pp. 6-15.

[20] Getachew Tesfaye, "Structure, biomass and net primary production in a dry tropical afromontane forest in Ethiopia". Addis Ababa University, Ethiopia.

[21] Muluken, N.B., Teshome S., Eyale B., "Above- and BelowGround Reserved Carbon in Danaba Community Forest of Oromia Region, Ethiopia: Implications for $\mathrm{CO} 2$ Emission Balance", American Journal of Environmental Protection. 2015, 4(2): 75-82. doi: 10.11648/j.ajep.20150402.11 
[22] Alefu C., Teshome S., Eyale B., "Carbon Stock in Woody Plants of Humbo Forest and its Variation along Altitudinal Gradients: The Case of Humbo District, Wolaita Zone, Southern Ethiopia", International Journal of Environmental Protection and Policy. 2015, 3(4): 97-103. doi: 10.11648/j.ijepp.20150304.13

[23] Murphy, P. G. and Lugo, A. E," Ecology of tropical dry forest", Ann. Rev. Ecol. Syst. 17:67-88, 1986.

[24] Brown, S. "Estimating biomass and biomass change of tropical forests" a Primer FAO Forestry Paper 1997,134:120130 .

[25] Demel Teketay "Germination ecology of 12 indigenous and 8 exotic multipurpose legu minous species from Ethiopia". Forest Ecology and Management 1996, 80: 209-223.

[26] Lüet, Yin JX, Jepsen MR and TangJW, "Ecosystem carbon storage and partitioning in a tropical seasonal forest in Southwestern China". Forest Ecology and Management 260: 1798-1803, 2010.

[27] Lasco RD, Guillermo IQ, CruzRVO, Bantayan NC \& Pulhin FB, "Carbon stocks assess ment of a secondary forest in Mount Makiling Forest Reserve", Philippines. Journal of Tropical Forest Science 2004, 16: 35-45.

[28] Lugo, A. E; Parrotta, J. A; and Brown, S, "Loss in species caused by tropical defore station and their recovery through management"1993, 22: 106-109.
[29] Moges, Y., Eshetu, Z., and Nune, S, "Current Status and Future Management Options In View of Access to Carbon Finances". Ethiopian Climate Research and Networking and the United Nations Development Programme (UNDP) Addis Ababa, Ethiopia 2010, PP.56.

[30] Munishi PKT, The Eastern Arc Mountains Forests of Tanzania: "Their Role in Biodiversity and Water Resources Conservation and Net Contribution to Atmospheric Carbon", $\mathrm{PhD}$ Thesis 2001, North Carolina State University, Raleigh, NC USA. pp.128.

[31] Munishi PKT \& Shear TH, "Carbon storage in afromontane rain forests of the Eastern Arc Mountains of Tanzania": their net contribution to atmospheric carbon. Journal of Tropical Forest Science 2004, 16: 78-93.

[32] Houghton RA,"Aboveground forest biomass and the global carbon balance" Global Change Biology 11: 945-958, 2005.

[33] Brady, N. C, "The Nature and Properties of Soils", $8^{\text {th }}$ ed., Macmillan, New York 1974.

[34] Powers, J.S., Schlesinger, W.H. "Relationships among soil carbon distributions and bio physical factors at nested spatial scales in rainforests of northeastern Costa Rica", 109:165-190, 2002. 